\title{
САБЛИ И ШАШКИ, КАК ЭЛЕМЕНТЫ ТРАДИЦИОННОЙ ВОЕННОЙ КУЛЬТУРЫ ДАГЕСТАНЦЕВ
}

\section{SABLES AND CHECKS AS ELEMENTS OF THE TRADITIONAL MILITARY CULTURE OF THE DAGESTANIANS}

\author{
A. Omarov \\ R. Magomedov
}

Summary: The article attempts to analyze the functional features, specifics and centers of production, the scale of the spread of sabers and checkers, as an important element of the military culture of the Dagestanis. The complex of factual material makes it possible to investigate this topic against the background of military-political events, to identify the ways in which these types of cold weapons fell into the territory of Dagestan, to determine the place and significance of sabers and sabers in the system of traditional mountain weapons. The characteristics of the studied types of weapons of Dagestan production are given, a comparative historical analysis with the Transcaucasian, Iranian, Russian, Indian models is carried out. Subject materials from the Derbent Museum-Reserve expand our understanding of the role of the saber and saber in the military culture of the Dagestanis, allow us to draw a conclusion about the deep historical roots of their production and objects of important material and sacred significance, to determine common features and differences with foreign samples.

Keywords: sabers and checkers, military culture, Dagestan, Derbent Museum-reserve, armourers, subject materials, Kubachi, VerkhneyeKazanishche, Gotsatl, Kazi-Kumukh.
Омаров Абдулкадыр Исаевич

д.и.н., профессор, Дагестанский государственный университет

levzerov@mail.ru

Магомедов Руслан Мухумаевич

С.н.с., Дербентский государственный историкоархитектурный и археологический музей-заповедник oliverkromvel93@mail.ru

Аннотация: В статье предпринята попытка проанализировать функциональные особенности, специфику и центры производства, масштабы распространения сабли и шашки, как важного элемента военной культуры дагестанцев. Комплекс фактического материала дает возможность исследовать данную тему на фоне военно-политических событий, выявить пути, по которым данные виды холодного оружия попадали на территорию Дагестана, определить место и значение сабель и шашек в системе традиционного горского вооружения. Дается характеристика исследуемых видов оружия дагестанского производства, проводится сравнительно-исторический анализ с закавказскими, иранскими, российскими, индийскими образцами. Предметные материалы из Дербентского музея-заповедника расширяют наши представление о роли сабли и шашки в военной культуре дагестанцев, позволяют сделать вывод о глубоких исторических корнях их производства и предметах важного материального и сакрального значения, определить общие черты и различия с иностранными образцами.

Ключевые слова: сабли и шашки, военная культура, Дагестан, Дербентский музей-заповедник, оружейники, предметные материалы, Кубачи, ВерхнееКазанище, Гоцатль, Кази-Кумух.
И сторически большая часть территории Дагестана занимало значительный участок древнего мирового пути, по которому осуществлялось значительная часть военно-политической и культурной коммуникации между Европой и Россией и восточным миром. Это предопределяло интерес к горной стране со стороны мировых держав. Это вынуждало местное население (феодальные образований и союзов сельских обществ уделять постоянное внимание состоянию военного дела, развивать вооружение, перенимать и использовать оружие иностранного производства. Между тем вопросы производства местного оружия, её специфика, отличия от других образцов, их разнообразие и пути попадания иностранного оружия на территорию Дагестана изучены недостаточно.

Исследованию дагестанского оружия и их декоративно-прикладной специфике посвящены несколько работ. В частности, это труд Аствацатурян Э.Г. (Дагестанское оружие. Махачкала, 2014), кандидатская дис- сертация Салмановой А.И. (Дагестанское оружие в XIX - начале XX вв. Махачкала, 2000). Частично эту проблему освещают такие дореволюционные авторы, как Пиралов А.С. (Краткий очерк кустарных промыслов Кавказа. Издание второе. СПб, 1913), Маркграф О.В. (Очерк кустарной промышленности Северного Кавказа с описанием техники производства. М, 1882), современные специалисты Кирилл Ривкин и Оливер Пинчо. (Оружие и военное дела Кавказа. Украина. Запорожье, 2011), Кузнецов А., Сидоров С. (Клинок на ковре. Записи коллекционера кавказского оружия. М. 2018), и некоторые другие. Однако тема нашего исследования в этих работах освещена фрагментарно, и в основном ограничивается XIX веком.

Поэтому основной целью нашего исследования является на базе разнообразного исторического, искусствоведческого, этнографического и предметно-материального материала, проанализировать роль шашки и сабли в формировании традиционной дагестанской военной культуры. 
Для этого необходимо решить несколько задач, в частности, охарактеризовать процесс и пути появления данных видов холодного оружия в Дагестане, определить главные центры местного производства, оценить степень распространения и значение сабли и шашки, как военных элементов горского вооружения, отличия подобного оружия от оружия иностранного производства.

Но, прежде чем перейти к конкретной теме данного исследования важно определить с историческим значением, такого важного для нашей темы термина, как «военная культура». Здесь важно отметить, что чёткого определение этого термина практически отсутствует. Однако, по данным В.И. Бажукова термин «военная культура» определяется как «качественная характеристика бытия военной сферы деятельности, степень совершенства ее развития, как системы в совокупности материальной и духовной составляющих». В структуре военной культуры, по мнению этого автора выделяются: военная культура общества, военная культура государства, военная культура армии (вооруженных сил) и военная культура личности. А элементами военной культуры признаются только те, которые приняты в обществе, то есть, имеют распространение и оказывают влияние на индивида. А общественный характер военной культуры, проявляется в том, что она привязана к определенному обществу, общности, социальной группе. То есть, каждое общество создает свою более или менее развитую военную культуру [8.].

Начнём с того, что специфика военной культуры Дагестана немного иная, чем выше обозначенная В.И. Бажуковым. Она, на территории Дагестана, в наиболее законченном виде сформировалась в период Имамата (в 40-50 годах XIX столетия) под руководством главы данного государственного образования имама Шамиля. Там существовали фактически все элементы данной культуры (армия, включающая разные роды войск, вооружение, наградная система, командование, этикет, устав и т д.) $[12$, с 13-132.].

Однако, за долго до этого, начиная с Позднего средневековья, (предположительно с конца XV века [4,с 32-44.] имелись «примитивные военные культуры», практически схожие друг с другом. Они включали в себя общее командование в каждом политическом образовании. В союзах сельских обществ военные предводители избирались советом старейшин на год [5,с 55-70.]) с военизированным отрядом. У феодальных правителей были свои профессиональные отряды «нукеры») [4,с 32-44.]. Кроме того, в случае необходимости набирались ополченцы. Существовала и своя особая система подготовки воинов, включая морально-психологическую составляющую. Эта сторона военного обучения, как и самобытная техника владения оружием, специфика тактики и стратегии в пе- риод боевых действий заслуживает отдельного исследования. В научной литературе, посвящённой военной истории Дагестана, вышеуказанные аспекты военной культуры практически не изучены. Между тем, с глубокой древности такие военные элементы, как производство оружия, приобретение боевых навыков, джигитовка и другие для дагестанских этносов оставались одними из ключевых в сложных военно-политических событиях, происходивших на территории Дагестана в различные эпохи. Об этом можно судить по довольно обширной научной литературе, посвящённой древнему периоду истории Дагестана (Амирханов Х.А., Тесаков А.С., Ожерельев Д.В. К датировке стоянки олдована Мухкай IIA в Дагестане // Бюллетень комиссии по изучении четвертичного периода. № 75. 2017., Гаджиев М.Г., Давудов О.М., Шихсаидов А.Р. История Дагестана с древнейших времён до конца XV в. Махачкала: ДНЦ РАН, 1996., Пикуль М.И. Эпоха раннего железа в Дагестане. Махачкала, 1967. Магомедов. М.Г. Древние государственные образования Дагестана. Махачкала, 2006. и т д.).

В военной культуре важнейшим образующим элементом является оружие, как один из существенных элементов экономического развития для многих этносов. Не являются в данном случае исключением и дагестанские этносы. Известный специалист по историческому оружиеведению Э.Г. Аствацатурян точно отмечает, что « с издревле, для населения Дагестана, как и для многих представителей народов Кавказа, производство оружия было одним способов существования»[2,с 3.].

О весомом значении оружия у дагестанских этносов в историческом пространстве ещё с древности также свидетельствуют и наскальные изображения на территории Дагестана, в частности районе сёл Капчугай, Ленинкент, Кумторкала, Эки-Булак. Там, некоторые представители древнего населения Дагестана изображены как лучники, всадники и т.д.[20,с 58.].

Поэтому вопросу известный кавказовед XIX столетия О.В. Маргграф не случайно отмечал, что Дагестан является одним из главных центров по производству оружия на Кавказе, где кроме известных оружейных центров (имеется ввиду Кубачи, Амузги и Харбук), практически у каждого этноса имеются ремесленники, которые изготавливают оружие, но относительно в малом количестве. «В Дагестане, кустарная промышленность занимает почти все рабочие руки различного населения горных округов, причем семейный труд распределяется так: женская половина семьи обрабатывает шерсть, а мужская готовит оружие»[19,с 206. ].

Здесь также надо признать, что оружие для дагестанских этносов имело значение не просто как ключевой элемент их военной культуры, оно являлось для них и важнейшим элементом сакральной культуры. Поэтому 
поводу здесь, как точно отмечает современный историк Атаев М.М., «оружие и материал, из которого его изготавливали на территории Дагестана, были окружены ореолом сверхъестественного могущества. Кинжал и шашка очень часто употреблялись дагестанцами в прошлом в качестве талисманов, ограждающих от нападения злых духов и от вредных влияний, чар, колдовства и прочего. Оберегая роженицу от всяких вредных воздействий, во время родов около нее клали обнаженную шашку» [6.]

На сегодняшний день о сакральном значении оружия у народов Дагестана свидетельствуют и несколько известных фактов, в том числе у табасаранцев. Так, в селении Чурдаф, по преданию якобы хранился меч арабского полководца Масламы, которого часто ошибочно отождествляют с легендарным распространителем ислама Абу-Муслимом, известным распространителем ислама в Нагорном Дагестане. С этим мечом жители этого населённого пункта совершали разные обряды, для него даже построили специальный домик. Об этом в ходе этнографической экспедиции современному этнографу Р.И. Сефербекову в августе 1997 года рассказали жители данного села. По его информации «хранился меч в ножнах, сплетенных из конопляных нитей («других ножен меч не принимал»), в особом сундуке («тавут»). Чтобы этот меч не заржавел, его смазывали курдючным салом. Приближаться к мечу можно было только ритуально чистым, после совершения намаза, в белых одеждах из домотканой шерстяной («шал») или конопляной («ир») материи. Рассказывают, что меч часто исчезал из сундука, вступал в битву с врагами, поражал их, а затем, весь в крови, вновь появлялся в сундуке.

Само селение, по данным Р.И. Сефербекова «враги обходили стороной, так как при приближении к нему по ним била молния. Один раз в год (возможно, это происходило в день весеннего равноденствия, когда отмечали праздник Эбелцан) меч демонстрировали перед взрослым мужским населением села». По словам старожилов, они помнят, как в детстве наблюдали из-за ограды вокруг священной рощи ритуал демонстрации меча. Хранитель меча вытаскивал его из ножен и несколько раз описывал им круги над своей головой со словами: «Вот меч, который нам оставил шейх Абу Муслим».[31, с 66-76.]

Такого же рода факт также зафиксировала и известный современный историк П.И. Тахнаева в селении Хунзах Хунзахского района. В этом селении, по данным П.И. Тахнаевой, «хунзахская сабля» (здесь имеется ввиду сабля Абу-Муслим шейха [9, с 5-7.]) использовалась в обряде «хвалчен бухьи» (в переводе с аварского на русский - привязывание сабли). Этот обряд проводился и для «освящении» выступления нуцала (хана) в военный поход. Также этот обряд практиковался при праздновании совершеннолетия сына нуцала (нуцал - титул правителя Аварского ханства), а иногда сабля использовалась «для прекращения сильного града»[32.].

В данном случае особо выделяются, наряду с кинжалами, и выше упомянутые сабли, а также шашки, появившиеся на исторической арене Дагестана с XIX века. Вероятно, сабли впервые на территории Северного Кавказа начали использовать ещё VIII веке нашей эры. Это подтверждают археологические данные из работы известного советского учёного Г.Ф. Корзухиной. Она, в частности, указывает что, на территории Северного Кавказа обнаружено довольно большое количество сабель (возможно это клинки сабель, так как целостное такого рода холодное оружие практически раскопать невозможно, особенно относительно раннего периода) датируемые VIII-IX веками и относящиеся к хазарскому типу [17,с 74-75.]. Эти данные Г.Ф. Корзухиной подтверждает и известный дагестанский историк- востоковед А.Р. Шихсаидов, сообщая, что в VIII - начале XI вв. на территории Дагестана большое распространение получили разнообразные железные изделия: сабли, копья, топоры наконечники стрел) [36, с 74-75.].

Однако, из дошедших до нас самых ранних образцов дагестанских сабель в полноценном виде, как пишет вышеупомянутая Э.Г. Аствацатурян, сохранились лишь образцы XVIII-XIX веков. На её взгляд эти дагестанские сабли испытали довольно большое влияние иранского оружия. Особо это влияние можно увидеть по рукояти и в ножнах. Такого вида клинки иранского типа производились в Амузги. [1,с34-35.] что представляется вполне вероятным, учитывая многовековой характер ирано-дагестанских взаимоотношений [11.].

Однако Кирилл Ривкин и Оливер Пинчо склоняются к тому, что дагестанские сабли менее схожи с иранскими, так как, по их мнению, у иранских сабель XVIII века рукоять однородная и тоньше, чем у дагестанских и грузинских. К тому же, дагестанские и грузинские клинки толще и шире, менее изогнуты, чем персидские сабельные клинки, а навершия рукояти изготовлены в форме лошади, орла или льва [14,с 96-98.].

Можно с определенной долей вероятности предположить, что дагестанские оружейники изготавливали сабли, как иранского типа, так и грузинского, так как и с грузинскими феодальными образованиями у дагестанских политических образований были тесные торговоэкономические связи, не говоря уже о политических [21, c 16-21.].

В данном вопросе также важно обозначить, что представляет сама «сабля» из себя, как материальный элемент военной культуры. Известный специалист по историческому оружиеведению А.Н. Кулинский отмечает, что сабли это - клинковое оружие с длинным изогнутым клинком, но с довольно простой гардой и рукояткой 
[12,с 25.].А сам этот термин, по данным историка Т.М. Ткачука, сформирован от венгерского слова «срыууа, что в переводе на русский язык означает «резать»[33,с49.] .

Данный вид холодного оружия, как местного производства, так и иностранного производства (в основном, турецкого и иранского, А.О., Р.М.) на территории Дагестана пользовался довольно большой популярностью, как местного образца, так и иранского и турецкого. Об этом, в частности, свидетельствуют данные Оружейного фонда Национального музея РД имени Алибека Тахо-Годи. В нём представлено немало образцов данного вида холодного оружия, которые в большинстве своём - это сабли, изготовленные в Иране и Турции, в основном датируемые XVIII-XIX веками. Из дагестанских сабель самые ранние датируются XVIII веков (точная дата изготовления не известна - А.О., Р.М.). Информации о месте изготовления данных экземпляров на территории Дагестана нет[22.].

Здесь также важно отметить, что на территории Дагестана в XIX веке также знали об индийских саблях. Об этом, в частности, свидетельствует индийская сабля, датируемая XIX веком (точное место изготовления, время и мастер изготовления не известны А.О., Р.М,), хранящаяся в фонде «Оружие и металлы» Дербентского музея-заповедника. Общая длина данной сабли 77 см, навершие рукояти медное, сделано в форме льва, длина клинка 65 см, изгиб 65 см, конец клинка обоюдно-острый, длина рукояти 8см, без учёта навершия, длина дола 40 см а ширина 0.2 см, долы на клинке сделаны с обоих сторон ближе к тупой стороне клика. Рукоять данного клинка имеет типичную медную гарду с эфесом. На клинке надпись на английском «Made in India».На клинке ближе к рукояти имеется рисунок растительной формы [10.]. С большой вероятностью можно утверждать что, это одна из разновидностей индийского тальвара (индийской сабли), появившегося на исторической арене в начале XIX века [34, с 228.].

Из уникальных, исторически значимых работ клинкового оружия, хранящих на территории Дагестана стоит выделить и так называемую «саблю Тимура». Она хранится в Национальном музее Дагестана имени А. Тахо - Годи под инвентарным номером 1553. Эта сабля якобы принадлежала среднеазиатскому завоевателю конца XIVначала XV века. Темирлану. В первой половине XVIII века эта сабля попала в руки иранского шаха Надира. Однако в ходе Андалалского сражения 1741 года на территории Дагестана, где войска данного шаха потерпели поражение от дагестанского ополчения, данный клинок попал в руки, наряду с другим его имуществом дагестанским ополченцам. С этого времени сабля оставалась в горах Дагестана во владении различных представителей местной знати. В 1936 году эта сабля была приобретена краеведческим музеем у жителя селения Хунзах У. Гусейнова. Что касается датировки данной сабли, то как по- казывают научные исследования относительно данного клинка, сделанные известным современным историком А.К. Аликберовым, то выходит что «эта сабля была изготовлена в XVIII веке персидскими мастерами по заказу самого Надир- шаха, стремившегося, видимо, таким образом подчеркнуть историческую значимость своих завоеваний»[3, с 3-7.].

Теперь, остановимся на роли и значении шашки. По данным вышеупомянутого А.Н. Кулинского, шашка это - оружие с длинным клинком с незначительной кривизной и с эфесом, состоящим только из рукояти с раздвоенной головой $[12$, с 27.].

Впервые шашка описана в Кабарде итальянцем Джани де Лукой в 1625 году. Сам данный термин, по данным известного историка и коллекционера оружия Алибека Казанбиева, происходит от черкесского слова «сашхо», что в переводе на русский язык означает «большой нож». Но при этом Алибек Казанбиев сообщает, что «когда на конференции по жизни и творчеству Абубакара Аймакинского я читал доклад об аварском оружии и высказал мысль о том, шашка по всем показателям, это изобретение дагестанское, Иса Абдулаев (почетный доктор Тбилисского университета) подтвердил эту мысль. Он сказал, что в Толковом словаре грузинского языка есть слово лекури (шашка леков). Лекури - шашка без перекрестия. Словарь составлен в конце XVII века, а значит, в это время уже в грузинском быту, на войне были шашки-лекури. Для грузин и раньше, и сегодня леки - это, аварцы»[18.].

Однако научно-исследовательские материалы А.Е. Савельева предлагают нам иную версию. По этим данным шашки появились у адыгов примерно в XII в. и долгое время сосуществовали параллельно с саблей, выполняя при этом иную функцию. По мнению А.Е. Савельева, «шашка же предназначена для боя с незащищенным противником и для отражения внезапного нападения. Даже портупея (от французского «porter» - «носить» и «ерее» - «шпага», часть военного снаряжения виде ремней различной длины, носимых военнослужащими через плечо и у бедра), [7.] предназначена для того чтобы можно было вынуть шашку из ножен и нанести удар, не меняя положение руки». Шашки, по мнению того же А.Е. Савельева, по мере уменьшения роли сабли и с меньшим количеством использования защитного снаряжения, стали преобладать у горцев в XVIII-XIX веках. Уже к 30 годам XIX века шашка, по мнению А.Е. Савельева, стала у горцев единственным образцом холодного оружия с длинным клинком. Оценивая этот тип оружия, барон Ф.Ф. Торнау, выполнявший на Кавказе ряд разведывательных миссий, писал, что «это последнее, любимое и самое страшное черкесское оружие состоит из сабельной полосы, в деревянных, сафьяном обтянутых ножнах, с рукояткой без защиты для руки. Шашка черкеса остра 
как бритва, и употребляется им только для удара, а не для защиты; удары шашки большей частью бывают смертельны»[29, с184-185.].

Столь высокая эффективность использования шашки,по мнению А.Е. Савельева связана, прежде всего, с особенностью ее конструкции. По его мнению, большинство образцов имеет сравнительно короткий (72-76 см) мало изогнутый клинок с рукоятью без защитной гарды. Оценивая последнюю деталь, А.Е. Савельев отмечает, что «этим смелым решением был уменьшен вес оружия на 1/6, 1/5 часть, кроме того, что немаловажно для рубящих клинков, данное изменение передвинуло центр тяжести вперед. Эти особенности шашки делали возможным нанесение ею мощных рубящих ударов в быстром темпе. Вместе с тем, для колющих ударов шашки приспособлены не были. Дагестанские шашки же были несколько длиннее и тяжелее черкесских [29, с 184-185,].

Однако, это отличие от черкесских шашек не помешало дагестанским шашкам получить большую популярность в XIX веке не только у местного населения. Немало дагестанских мастеров-оружейников того периода известны как мастера первоклассно изготавливавшие и шашки, не говоря уже о кинжалах. Среди них Базалай из Верхнего Казанище [30] и Шахманай из Гелли, чьи работы из-за высокого качества пользовались большой популярностью не только у местного населения но и у русских офицеров того периода[35.].Здесь, среди дагестанских оружейников, которые изготавливали шашки в XIX столетии также следует отметить и Чаландара из Гамсутля, чьи работы получили большую популярность в тот период [25.].

Крупными центром производства холодного оружия в XVIII-XIXвеках на ряду с Кубачи, Амузги, Ругуджа, Унцукуль, Гоцатль так же являлся и Кази-Кумух. Так, одна из дагестанских шашек, изготовленная в Кази- Кумухе и датируемая XIX веком (если быть точнее 1289 годом по хиджры, то есть между 1872/1873 годами) храниться в Эрмитаже. По данным В.Н. Образцова, клинок этой шашки выкован из превосходной булатной стали. Вдоль обуха расположены два дола. Лезвие полировано, боевой конец обоюдоострый. На лицевой стороне клинка, у пяты, выполнено гравированное изображение дракона. На другой стороне помещена арабская надпись, содержащая имя мастера - «Мохаммед», дату создания - «1289 [год хиджры, то есть 1872/1873]» и цитату из Корана. Рукоять заключена в рамку из вороненой стали с растительным узором, выполненным золотой насечкой, и обложена пластинками белой кости с инкрустацией золотой проволокой (орнамент «мархарай»). Таким же образом оформлен и прибор оклеенных черной кожей ножен. К ножнам прикреплена кожаная перевязь с металлическим набором [23,с 138. ].
Как сообщает известный историк конца XIX - начало XX века Пиралов А.С., который изучал кустарную промышленность Кавказа, в некоторых дагестанских шашках узор « представляет красивую комбинацию узоров, исполненных глубокой гравировкой, чернью и позолотою, на отдельных частях имеется насечка по стали золотом, 3 медальончика в середине и у рукоятки сделаны разноцветною эмалью, а самая рукоятка и середина шашки состоят из слоновой кости с насечкой узоров из червонная золота» [24, с 89.].

Здесь также следует добавить, что с XIX столетия на территории Дагестана большое распространение получили русские шашки. Об этом, в частности, свидетельствуют две шашки, хранящиеся в фонде «Оружие и металлы» Дербентского музея-заповедника:

Первая шашка, её общая длина 90.9 см, длина клинка 77.5, изгиб 76 см, но изгиб неглубокий, две долы с обоих сторон ближе к тупой стороне клинка, у первой долы длина $61 \mathrm{~cm}$, ширина 2мм, у второй 58 см, ширина также 2 мм, рукоять сделан из пластика, а её длина 10 см, навершия на рукояти шашки отсутствует, вместо неё закрученная гайка. Ножны сделаны из дерева, конец и начало ножен закреплены латунными деталями, на ножнах ближе к началу ножен также имеется латунно кольцо для поясного ремня [26.].Это шашка, как показывает научноисследовательская работа А.Н. Кулинского - драгунская солдатская образца 1881 года. Она заменила в 1881 году кавалерийские, драгунские и пехотные сабли, а также кирасирские палаши у всех офицеров и генералов, которые им были положены[13, с150-153.].

Вторая шашка, её общая длина 88 см, длина клинка $74 \mathrm{~cm}$, ширина у основания 4 см, длина рукояти 14 см, долы расположены с обоих сторон ближе к тупой стороне клинка, длина первой долы 62.9 см, длина второй долы 57.3 см. Длина ножен 84.9 см, на конце латунная закладка для закрепления ножен, сами ножны сделаны из дерева, но покрыты кожей, на ножнах также имеется ремень. Клинок стальной, незначительной кривизны, однолезвийный, с двумя узкими долами у обуха. Боевой конец двухлезвийный [27.]. По данным А.Н. Кулинского, это казачья шашка нижних чинов образца 1904 года. Шашки такого образца были приняты на вооружение нижних чинов кавказских казачьих войск, причем шашки подобного типа применялись в этих войсках и раньше. Приказ по военному ведомству 133 от 1904 года лишь частично регламентировал размеры оружия и его внешний вид. Шашка подобного типа использовались и после 1917 года [13, с 165-167.].

Но, к сожалению, история данных шашек, вернее, кому они принадлежали и как они попали в фонд музея не известно. Возможно, они принадлежали офицерам в разное время служившим в Дербенте в конце XIX - на- 
чало XX века.

В целом, подводя итог данного исследования, с сожалением нужно признать, что в научно-исследовательских работах, посвящённых военно-политической истории Дагестана, роль оружия в том числе роль сабли и шашки, практически не освещёна. Даже в крупных работах посвященных таким военно-политическим событиям, как война с Надир шахом (Сотавов Н.А. Крах «Грозы Вселенной» в Дагестане. Махачкала: Эпоха, 2013. - 304 с., Гаджиев В.Г. Разгром Надир-шаха в Дагестане.Махачкала, 1996.) и Кавказская война XIX века (Дадаев Ю.У. Вооружённые силы государства Шамиля. Волгоград, 2016.,Кругов А.И., Нечитайлов М.В. Вооруженные силы имамата горцев Северного Кавказа 1829-1859 гг. М., 2016.) роль сабли и шашки, как традиционного системного элемента рукопашного боя практически не освещена. В тоже время, объективности ради надо признать, что внимание этих авторов было занято другими военно-политическими сюжетами, а не изучением специфики и особенностей производства и использования тех или иных видов холодного оружия в Дагестане. Определенное место занимают сведения о различных видах огнестрельного оружия (ружья, пистолеты, артиллерия), которое активно использовалось в этих событиях.

Приведенные материалы также позволяют сделать следующие выводы:

1. Оружейное производство, в частности сабель и шашек имеют глубокие исторические корни на территории Дагестана наряду с аналогичным производством в таких державах, как Иран, Турция и Россия и в некоторых других оружейных центрах Кавказа.
2. Производство и масштаб распространения холодного клинкового оружия показывает их роль в военно-политической и повседневной жизни дагестанских этносов, как необходимые для самообороны виды холодного оружия, предметов существенного материального и сакрального значения.

3. Рассмотренные материалы также показывают, что на территории Дагестана производство сабель и шашек имели свои технические особенности, отличающие их от подобного рода производства в других областях Кавказа и странах, что не мешало местным оружейникам производить конкурентно-способный изделия, в частности шашки и сабли. Однако, при этом многие декоративно-прикладные и технические элементы дагестанских шашек и сабель схожи с иранскими, турецкими и некоторыми другими северо-кавказскими образцами, что позволяет говорить о взаимном влиянии технологий производства холодного клинкового оружия.

Вместе с тем следует отметить, что довольно слабо изучены в современной, в советской, и досоветской историографии социально-бытовая роль сабли и шашки в повседневной жизни дагестанского населения, с момента их появления на исторической арене Дагестана. Очевидно, что шашки и сабли наряду с другими видами холодного оружия, как местного, так и иностранного производства( Иран, Турция, Россия, Индия), активно использовались на территории Дагестана и занимали важное место в традиционной военной культуре местных народов.

\section{ЛИТЕРАТУРА}

1. Аствацатурян Э.Г. Дагестанское оружие. Махачкала: Эпоха, 2014. -306 с.

2. Аствацатурян Э.Г. История оружейного и серебренного производства на Кавказе в XIX-XX вВ. -M, 1977.-Ч 1.- 259 с.

3. Аликберов А.К. Надписи на сабле, датированной 473 г. х. // Письменные памятники и проблем истории культуры народов Востока. XXIV годичная научная сессия ИВ АН СССР (доклады и сообщения) 1989 Часть І.- М., 1991.

4. Алиев Б.Г. Служилая группа дагестанских феодальных владений // История, археология и этнография Кавказа. 2012. -Т. 8. -№1.- С. $32-44$.

5. Алиев Б.Г., Умаханов М.-С.К. Союзы сельских общин в борьбе за независимость Дагестана в XVII - первой половине XVIII в. // Освободительная борьба народов Дагестана в эпоху средневековья.- Махачкала, 1986.-123 с.

6. Атаев М.М. Оружие храбрых. http://www.gazavat.ru/history3.php?rub=19\&art=140

7. Александр Харалужный. Кобура и портупея. История и происхождение терминов. https://topwar.ru/171758-kobura-i-portupeja-istorija-i-proishozhdenieterminov.html.

8. Бажуков В.И. Понятие военной культуры: проблемы становления. file:///C:/Users/User/Downloads/ponyatie-voennoy-kultury-problemy-stanovleniya.pdf

9. Ислам на территории бывшей Российской империи. Энциклопедический словарь. Выпуск 2. M,1999. 166 с.

10. Индийская сабля XIX века. ГБУ Дербентский государственный историко-архитектурный и археологический музей-заповедник, Ф. Оружие и металлы. КП 1576.

11. Ирано-дагестанские культурно-исторические связи.- Махачкала, 2006.- 281 с.

12. Кулинский А.Н. Методические рекомендации. Атрибуция и описание некоторых видов холодного и ручного метательного оружия, и штыков.- СПб, 2007. -225 c. 
13. Кулинский А.Н. Русское холодное оружие XVIII-XX вв. - СПб, 2001. Т.1.- 381 с.

14. Кирилл Ривкин и Оливер Пинчо. Оружие и военное дела Кавказа. Украина.- Запорожье, 2011. -124 с.

15. Кузнецов А. и Сидоров С. Клинок на ковре. Записи коллекционера кавказского оружия.- М., 2018 г.-335 с.

16. Кругов А.И., Нечитайлов М.В. Вооружённые силы Имамата горцев Северного Кавказа. Изд. Русские витязи.- М.,2016.- 170 c.

17. Корзухиной Г.Ф. Из истории древнерусского оружия XI в. -M., 1950. https://vk.com/doc23420940_302750844?hash=1d0ccf85df46207823\&dl=1f613f85220 $6 \mathrm{cf4} 4 \mathrm{c3e}$

18. Казанбиев Алибек. Кавказская шашка. https://chernovik.net/content/sredniy-klass/kavkazskaya-shashka

19. Маркграф О.В. Очерк кустарной промышленности Северного Кавказа с описанием техники производства. М, 1882. 288 c.

20. Мерзоев Ш.А., Мерзоева А.Ш. /Героические истоки и историко-педагогические предпосылки формирования Дагестанского народного патриотизма.// Известия ДГПУ.-№2.- Махачкала, 2009.

21. Османов А.И. / К вопросу о торгово-экономических и культурных связях Дагестана и Грузии (с древнейших времен до середины XIX в.). Вестник института ИАЭ. 2010. № 4.

22. Оружейный фонд Национального музея Республики Дагестан им. АлибекаТахо-Годи. 25.02.20.

23. Образцов Вс.Н. Оружие Востока в собрании Эрмитажа.- СПб, 2014.- 228с.

24. Пиралов А.С. Краткий очерк кустарных промыслов Кавказа. Издание второе. - СПб, 1913.-128 с.

25. Потомственный мастер-ювелир из Гоцатля Магомед Джамалудинов более 60 лет работает на своемпоприще. https://riadagestan.ru/news/culture/ potomstvennyy_master_yuvelir_iz_gotsatlya_magomed_dzhamaludinov_bolee_60_let_rabotaet_na_svoem_poprishche/

26. Русская шашка образца 1881 года. ГБУ Дербентский государственный историко-архитектурный и археологический музей-заповедник, Ф. Оружие и металлы. КП 722. Инв. 225.

27. Русская шашка образца 1904 года. ГБУ Дербентский государственный историко-архитектурный и археологический музей-заповедник, Ф. Оружие и металлы. КП 1656.

28. Салмановой А.И. Дагестанское оружие в XIX - начале XX вв. Диссертация ... канд. исторических наук : 07.00.02. - Махачкала, 2000. - 206 с.

29. Савельев А.Е. Кавказское оружие на вооружении Российской императорской армии и казачьих войск // Теория и практика общественного развития. 2012. № 1.

30. Сапиулла Багаутдинов. Непревзойдённые булатники Кумыкии. http://kumukia.ru/?id=1594.

31. Сефербеков М.Р. Почитание меча Абу Муслима в селении Чурдаф: из истории одного земледельческого культа табасаранцев (традиции и современность) // Исламоведение. 2018. Т. 9.- № 3.

32. Тахнаева П.И. Знамя и сабля шейха Абу-Муслима:чохские исламские реликвии. http://www.kunstkamera.ru/files/lib/978-5-88431-294-4/978-5-88431294-4_06.pdf

33. Ткачук Т.М. Старинное оружие и доспехи: новый век. -Донецк:Сталкер, 2005. -250 с.

34. Харви Дж. С Уизерс. Мечи и сабли (большая энциклопедия). Эксмо, 2011.- 256 с.

35. ХосарХосаров. 0 великом мастере Шахманаеиз Гели. https://yoldash.ru/people-and-time/0_velikom_mastere_SHakhmanae_iz_Geli/

36. Шихсаидов А.Р. Ислам в средневековом Дагестане (VII—XV вв.). - Махачкала, 1969.-251 c.

(с) Омаров Абдулкадыр Исаевич (levzerov@mail.ru), Магомедов Руслан Мухумаевич (oliverkromvel93@mail.ru).

Журнал «Современная наука: актуальные проблемы теории и практики» 